\title{
Transcatheter tricuspid valve-in-valve replacement in two patients with Ebstein anomaly: technical considerations
}

\author{
Kay Kronberg ${ }^{1}$ (D) Malena Horn ${ }^{1} \cdot$ Fritz Mellert $^{2} \cdot$ Albrecht Elsässer $^{1}$
}

Received: 2 August 2020 / Accepted: 1 October 2020 / Published online: 9 November 2020

(c) The Author(s) 2020

\section{Graphical abstract}

Transcatheter Tricuspid Valve-in-Valve Replacement Technical Considerations

- Detailed anatomical planning with imaging and meticulous device knowledge

- Vascular access to match anatomic valve position

- Advancing a balloon catheter into the pulmonary artery to avoid capturing right ventricle structures

- Exchange to a stiff wire establishing a smooth curve

- Predilatate the Biovalve with a balloon slightly lower than the true inner valve diameter

- Prepare the new valve on the delivery system for tricuspid use with accurately check of valve direction

- Consider rapid pacing, in tricuspid valve the pacemaker position may be atrial, better coronary sinus or preexisting leads could be used

- Check position of implanted valve, it should stick out proximal for better seal. Be aware of shortening of the implantated valve through balloon dilatation

- Implant the valve with balloon high pressure

- Check conical shape of the implanted valve

- Perform angiography and pressure recordings

- Perscribe medication and plan follow up visits

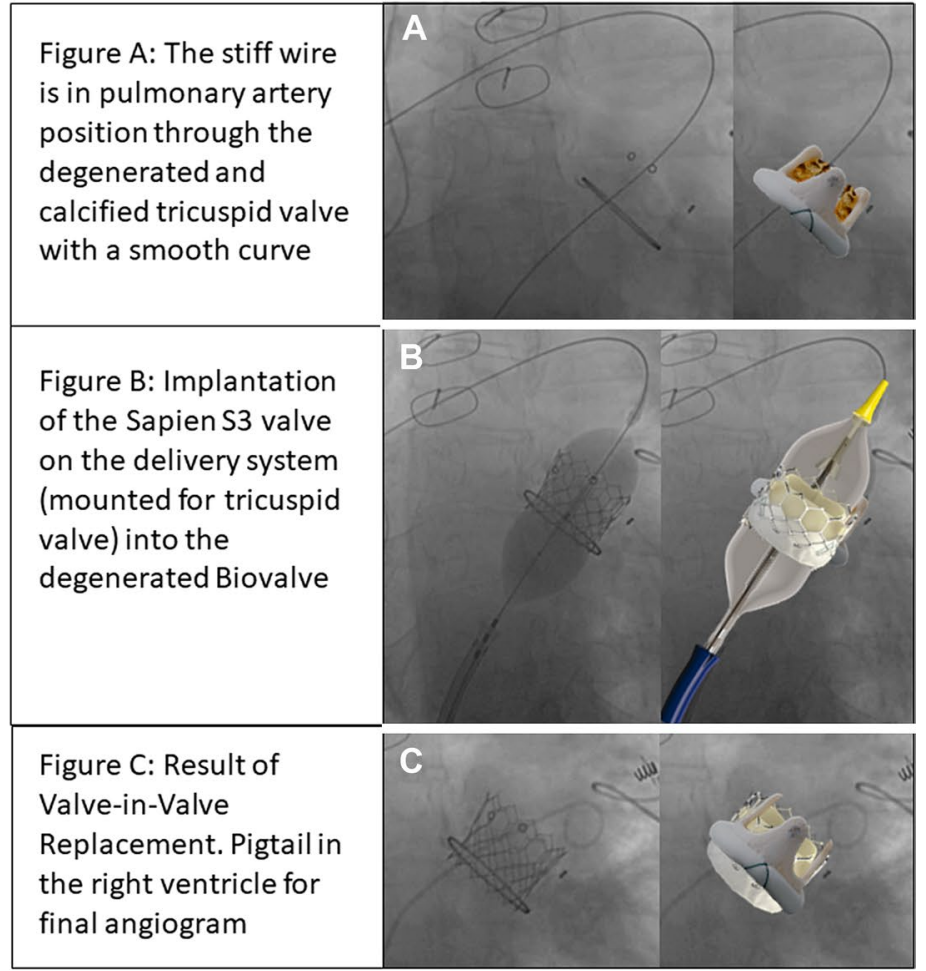

Electronic supplementary material The online version of this article (https://doi.org/10.1007/s00392-020-01756-0) contains supplementary material, which is available to authorized users.

Kay Kronberg

kronberg.kay@klinikum-oldenburg.de

1 Klinikum Oldenburg - Universitätsklinik für Innere Medizin - Kardiologie, Oldenburg, Germany

2 Klinikum Oldenburg - Universitätsklinik für Herzchirurgie, Oldenburg, Germany 
Sirs:

In patients with Ebstein anomaly, the tricuspid valve leaflets are attached to the walls and the septum of the right ventricle. This often leads to tricuspid regurgitation so that in some patients, surgical valve replacement has to be performed. Particularly in young patients, an implanted bioprosthesis bare the risk of early degeneration und dysfunction. It is noteworthy that in many cases, a redo operation bears a high risk of mortality and morbidity. Therefore, transcatheter tricuspid valve-in-valve implantation (TVIV) can be an alternative to a redo surgery, especially in patients with complex cardiac anatomy $[1,3-6,9,10]$.

In contrast to the common valve-in-valve therapy in aortic position, there are only a few results for the tricuspid position, but reported outcomes are often excellent. Most of the cases show impressive improvement concerning the measured mean gradient and the clinical status. Problems like tricuspid valve dysfunction, endocarditis or leafletthrombosis are uncommon after a valve-in-valve therapy $[1,10]$.

We report our experience of TVIV in two patients with Ebstein anomaly. The first patient (patient 1) is a 57-yearold man who presented in NYHA class III with recurrent dizziness, shortness of breath and oedema. A 2/6 diastolic murmur was audible, the electrocardiogram documented a sinus rhythm. He had a $33 \mathrm{~mm}$ HANCOCK II (MEDTRONIC, Minneapolis) tricuspid valve replacement at the age of 39 years. Echocardiography showed a degenerated and heavily sclerosed HANCOCK II prosthesis with an elevated mean pressure gradient of $8 \mathrm{mmHg}$ (Fig. 1b, video 2). Computed tomography (CT) revealed a massive right atrial dilatation (Fig. 1a, b, video 1). With the age of 48 years, the patient developed a third degree AV block and received a pacemaker. Because of his tricuspid bioprosthesis, epicardial electrodes had to be utilized. On admission, the pacemaker test showed battery depletion.

The second patient (patient 2) is a 34-year-old male with Ebstein anomaly and Wolff-Parkinson-White syndrome. He received an ablation therapy of an accessory pathway at the age of 22 years. Two years later, a Carpentier-Edwards PERIMOUNT bioprosthesis (Edwards Lifesciences Corporation; Irvine, Calif) was implanted due to severe tricuspid insufficiency. He presented with shortness of breath and oedema in NYHA class III. On transthoracic echocardiography, the PERIMOUNT bioprosthesis was heavily degenerated and sclerosed (Fig. 2a) with a breath depending mean gradient of 10 to $14 \mathrm{mmHg}$ across the valve (Fig. $2 \mathrm{~b}$ ).

For the discussion of the treatment options, all available imaging studies were revisited in the heart team (CT, echocardiography in both patients and additional invasive monitoring in patient 1 ).

The $33 \mathrm{~mm}$ HANCOCK II valve (Medtronic) had an outer diameter of $33 \mathrm{~mm}$ and a true inner diameter of $30 \mathrm{~mm}$, it was heavily sclerosed (Fig. 1a, b, video 3 ). The $33 \mathrm{~mm}$ PERIMOUNT bioprosthesis (Edwards Lifesciences) in patient 2 had an outer diameter of $33 \mathrm{~mm}$ and a true inner diameter of $28.5 \mathrm{~mm}$.

Due to these sizes, the Edwards SAPIEN 3 Transcatheter Heart Valve (Edwards Lifesciences Corporation; Irvine, Calif) with an outer diameter of $29-29.5 \mathrm{~mm}$ and an expanded height of $22.5 \mathrm{~mm}$ seemed suitable for both patients $[2,7,8]$.

Additionally, it seems that Ebstein patients with surgically implanted tricuspid bioprosthesis have a favourable anatomic position for transcatheter valve-in-valve implantation. In our patient 1 , the prosthetic valve ring showed a $45^{\circ}$ angle to body centre line; in patient 2 , we found a $40^{\circ}$ angle (Figs. 1a, c, 2c). On possible explanation might be the significantly enlarged right atrium and the need of sewing the initial tricuspid prosthetic valve to the fibrous part of the septum. This anatomical situation and the high risk of reoperation in Ebstein anomaly encouraged our decision towards a tricuspid valve-in-valve procedure $[1,4-9,10]$.

After for both patients informed consent has been obtained, we started the intervention in our hybrid operating room in general anaesthesia. Because of the $40-45^{\circ}$ valve angles, we choose the right femoral vein for vascular access. After placing a short $6 \mathrm{~F}$ sheath, we passed a balloon wedge pressure catheter 110/6F (Arrow Medical, Kington, UK) through the sclerosed tricuspid valve into the pulmonary artery. Using a floating catheter, we avoided to capture the existing right ventricular structures. Hemodynamic values were taken, whereas the invasively measured mean gradient was $8 \mathrm{mmHg}$ in patient 1 and $12 \mathrm{mmHg}$ in patient 2 . On fluoroscopy, the massive valve calcification in the first patient could be observed (video 3).

To ensure a good wire support for balloon angioplasty, we placed an Amplatzer extra Stiff Wire 260 (Cook Medical Inc.; Bloomington, Ind) in patient 1 and a Lunderquist 300 wire (Cook Medical Inc.) in patient 2 through the wedge pressure catheter. With a $28 \mathrm{~mm}$ Cristal Balloon Catheter 28/50/110 (Balt, USA, Medical Devices, Irvine, CA), we predilated the tricuspid bioprosthesis too fully balloon expansion in both patients (Figs. 1c, 2c, video 4). The position of the balloon was stable during the cardiac cycle.

After preparation, the SAPIEN 3 valve system could be gently advanced over the stiff wire (Fig. 2d). Due to the favourable angle of the implantated valves in both Ebstein patients, the orthogonal alignment of the wire with the ring of the bioprosthesis was given (Figs. 1c, d, 2c, d).

To guarantee a stable SAPIEN position throughout the heart beat cycle, we needed in the first patient no rapid pacing due to the heavily calcified prosthesis. In the second patient, we used atrial pacemaker overstimulation at a rate of 140/min to minimize heart movement during implantation (Electrode BP2502-10 Biosensors international, Singapore), 

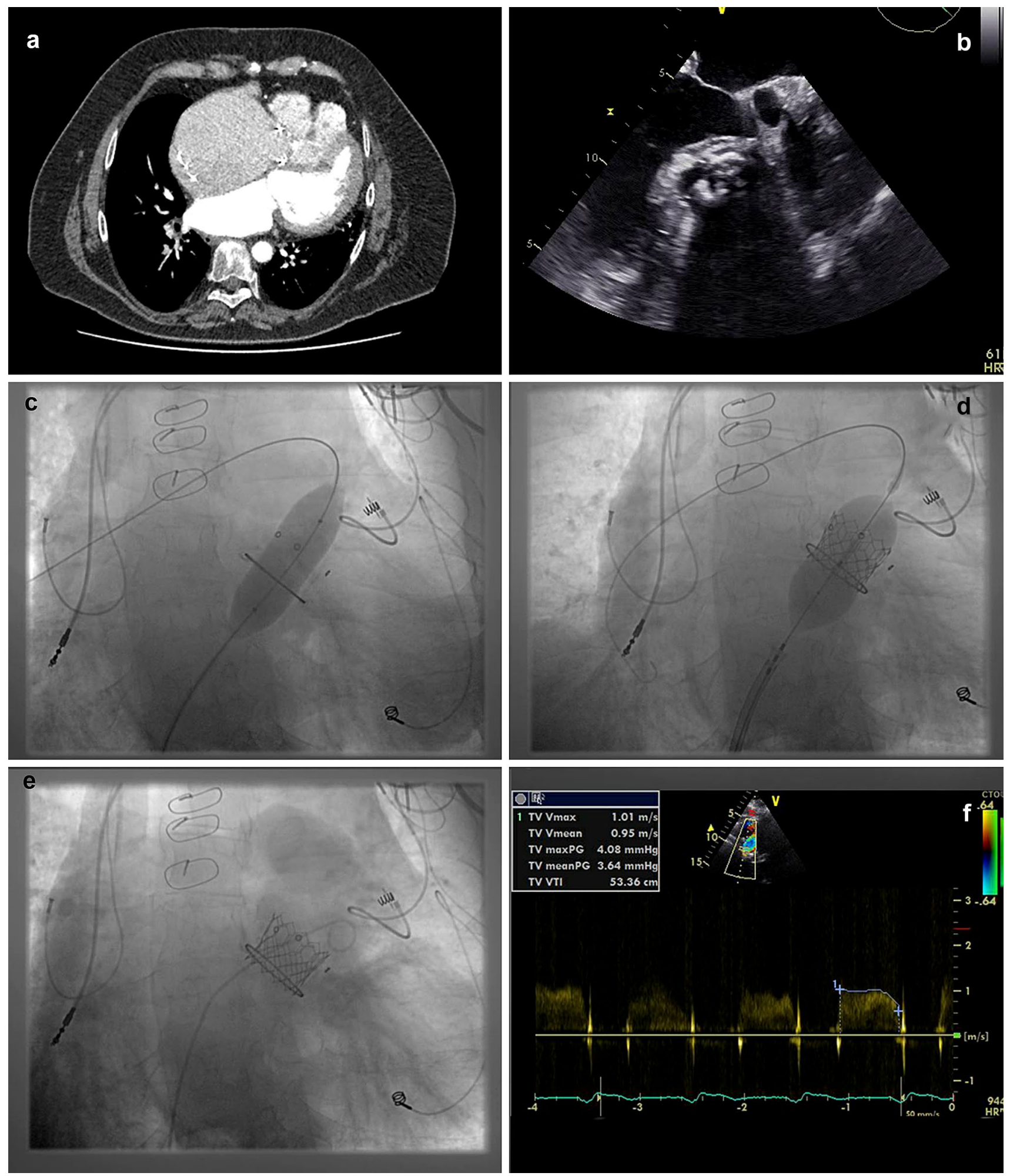

Fig. 1 CT, transesophageal echocardiography, valve placement and final Doppler

(Fig. 2c, d, f, video 5). Alternatively, a deflectable pacemaker electrode could have been positioned over the coronary sinus in middle cardiac vein to realize more rapid ventricular stimulation in patients with tricuspid prosthesis [3].
To ensure an appropriate position, the SAPIEN 3 prosthesis has to be placed about $10 \%$ above the sewing ring of the implanted valve. The proximal portion of the $29 \mathrm{~mm}$ SAPIEN 3 valve is wrapped with a relatively long 

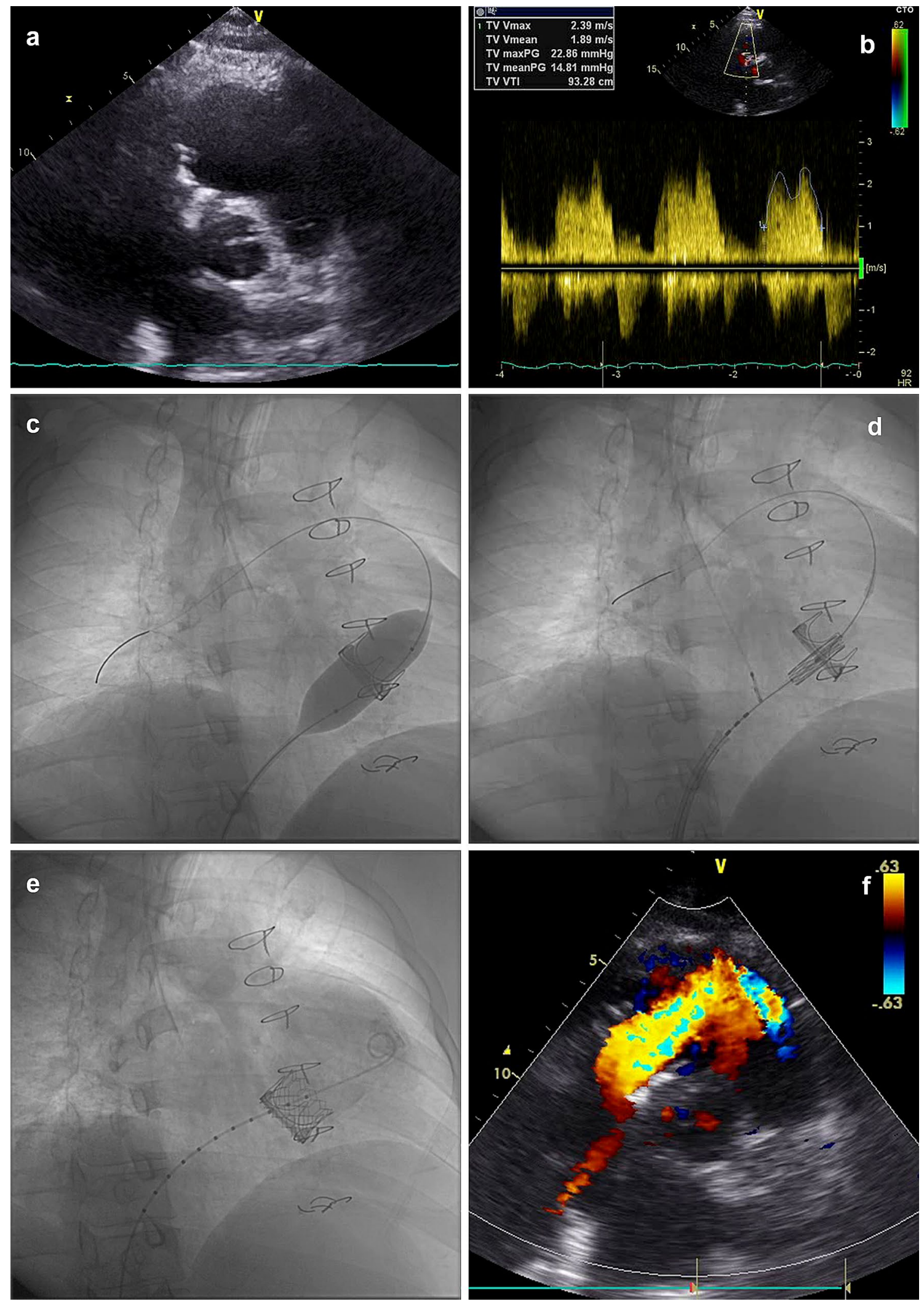

Fig. 2 TTE, Doppler, valve placement and final colour Doppler 
inner skirt $(11.6 \mathrm{~mm})$ and a smaller outer skirt $(8.1 \mathrm{~mm})$ of polyethylene terephthalate (PET) for sealing. The foreshortening while implantation is mainly on the inflow side and around $8.5 \mathrm{~mm}$ from a crimped height of $31 \mathrm{~mm}$ to expanded height of $22.5 \mathrm{~mm}$. After implantation with this precaution, the cobalt chromium stent of the SAPIEN 3 lies minimally proximal to the preexisting valve on fluoroscopy. This way the outer skirt of the SAPIEN 3 valve seals up at best to the sewing ring of the existing valve [2, $7,8]$. For a save and complete sealing, the SAPIEN 3 valve received a final balloon dilatation and a conical shape of the SAPIEN 3 stent could be seen (Figs. 1e, 2e, f, video 6).

We ended the intervention with a competent valve and a mean gradient of $4 \mathrm{mmHg}$ in patient 1 and of $5 \mathrm{mmHg}$ for patient 2. The total fluoroscopy time was $12.3 \mathrm{~min}$ for patient 1 and 15.9 min for patient 2 . The procedure time was $80 \mathrm{~min}$ and $75 \mathrm{~min}$. The pacemaker device in patient 1 has been replaced in the same narcosis. Both patients recovered well and showed good valve function with no apparent valve leakage on echocardiography (Figs. 1f, 2f, video 7).

Leaflet thrombosis is an uncommon but important complication after valve-in-valve therapy, especially in tricuspid position, in which risks of bioprosthetic valve thrombosis is higher than in other positions not depending on the implanted valve type [10,4]. This concern is even increased due to Ebstein anomaly, most likely caused by the right atrium and RV enlargement and abnormal RV diastolic hemodynamics [10].

Given these conditions, it is worth considering the use of anticoagulant or dual antiplatelet therapy rather than a single antiplatelet agent. There are approximately half of Ebstein patients with TVIV treated with ASS as antiplatelet therapy and the other half additionally with anticoagulants like coumarin derivates $[1,4,10]$.

Our 57-year-old patient 1 could be discharged 5 days after the procedure. Due to intermitting atrial fibrillation, the discharged therapy was ASS $100 \mathrm{mg}$ and Edoxaban $60 \mathrm{mg}$. Our 34-year-old patient 2 was discharged on the fourth day after the procedure. He received a combination of ASS $100 \mathrm{mg}$ and Clopidogrel $75 \mathrm{mg}$ for 3 months. Endocarditis prophylaxis and ASS $100 \mathrm{mg}$ should be prescribed lifelong [4].

On follow-up, there was no stenosis and no valve insufficiency on echocardiography in our two patients. They both had good RV functions and were in a stable condition with no oedema. After 9 months, the mean gradient was $3 \mathrm{mmHg}$ in patient 1 (video 8 ) and after 3 months, the mean gradient was $5 \mathrm{mmHg}$ in patient 2 (video 9).

Mid-term valve-related outcomes after transcatheter tricuspid valve-in-valve replacement are promising in a data collection of TVIV 306 cases [1] and in 81 Ebstein patients [10].

According to our experience, the procedure is technically feasible with good results but requires detailed anatomical planning and meticulous device knowledge $[2,7]$.
Funding Open Access funding enabled and organized by Projekt DEAL.

Open Access This article is licensed under a Creative Commons Attribution 4.0 International License, which permits use, sharing, adaptation, distribution and reproduction in any medium or format, as long as you give appropriate credit to the original author(s) and the source, provide a link to the Creative Commons licence, and indicate if changes were made. The images or other third party material in this article are included in the article's Creative Commons licence, unless indicated otherwise in a credit line to the material. If material is not included in the article's Creative Commons licence and your intended use is not permitted by statutory regulation or exceeds the permitted use, you will need to obtain permission directly from the copyright holder. To view a copy of this licence, visit http://creativecommons.org/licenses/by/4.0/.

\section{References}

1. McElhinney DB, Cabalka AK, Aboulhosn JA, Eicken A, Boudjemline Y, Schubert S, Himbert D, Asnes JD, Salizzoni S, Bocks ML, Cheatham JP, Momenah TS, Kim DW, Schranz D, Meadows J, Thomson JD, Goldstein BH, Crittendon I, Fagan TE, Webb JG, Horlick E, Delaney JW, Jones TK, Shahanavaz S, Moretti C, Hainstock MR, Kenny DP, Berger F, Rihal CS (2016) Dvir D and valve-in-valve international database $R$. transcatheter tricuspid valve-in-valve implantation for the treatment of dysfunctional surgical bioprosthetic valves: an international Multicenter Registry Study. Circulation 133:1582-1593

2. Dr. Vinayak Bapat; UBQO Limited. (2020). Valve in Valve (Mitral) (Version 2.2) [Mobile application software]. Retrieved from https://www.pcronline.com/PCR-Publications/PCR-mobil e-apps/Valve-in-Valve-Mitral-app.

3. Loyalka P, Nascimbene A, Metz B, Gregoric ID, Raman AS, Kar B (2017) Transcatheter tricuspid valve-in-valve replacement with an edwards sapien 3 valve. Tex Heart Inst J 44(3):209-213. https ://doi.org/10.14503/THIJ-15-5639 ((Published 2017 Jun 1))

4. Mcelhinney DB, Aboulhosn JA, Dvir D, Whisenant B, Zhang Y, Eicken A, Ribichini F, Tzifa A, Hainstock MR, Martin MH, Kornowski R, Schubert S, Latib A, Thomson JDR, Torres AJ, Meadows J, Delaney JW, Guerrero ME, Salizzoni S, El-Said H, Finkelstein A, George I, Gewillig M, Alvarez-Fuente M, Lamers L, Cheema AN, Kreutzer JN, Rudolph T, Hildick-Smith D, Cabalka AK (2019) Mid-term valve-related outcomes after transcatheter tricuspid valve-in-valve or valve-in-ring replacement. J Am Coll Cardiol 73(2):148-157

5. Webb JG, Mack MJ, White JM, Dvir D, Blanke P, Herrmann HC, Leipsic J, Kodali SK, Makkar R, Craig Miller D, Pibarot P, Augusto Pichard J, Satler LF, Svensson L, Alu MC, Suri RM, Leon MB (2017) Transcatheter aortic valve implantation within degenerated aortic surgical bioprostheses-PARTNER 2 Valvein-Valve Registry. J Am Coll Cardiol 69(18):2254-2262

6. Grondahl BJ, Gaurav Dhar DO (2019) Valve in valve in valve. JACC Case Rep 1(4):468-470

7. Alia N, Rahee R (2015) Bapat Vinayak (2016): Challenges in valve-in-valve therapy. J Thorac Dis 7(9):1501-1508. https://doi. org/10.3978/j.issn.2072-1439.2015.06.16

8. Shivaraju A, Michel J, Frangieh AH, Ott I, Thilo C, Schunkert H, Kastrati A, Leon MB, Dvir D, Kodali S, Bapat V, Guerrero M, Kasel AM (2018) Transcatheter aortic and mitral valve-in-valve implantation using the edwards sapien 3 heart valve. J Am Heart Assoc. https://doi.org/10.1161/JAHA.117.007767)

9. JACC Cardiovascular Interventions (2011): Valve-in-Valve Transcatheter Aortic Valve Implantation for Degenerated 
Bioprosthetic Heart Valves. In: https://interventions.onlinejacc .org/content/4/11/1218 (Volume 4, Issue 11, November 2011 DOI: 10.1016/j.jcin.2011.07.015).

10. Taggart NW, Cabalka AK, Eicken A, Aboulhosn JA, Thomson JDR, Whisenant B, Bocks ML, Schubert S, Jones TK, Asnes JD, Fagan TE, Meadows J, Hoyer M, Martin MH, Ing FF, Turner DR,
Latib A, Tzifa A, Windecker S, Goldstein BH, Delaney JW, Kuo JA, Foerster S, Gillespie M, Butera G, Shahanavaz S, Horlick E, Boudjemline Y, Dvir D, McElhinney DB, Registry V (2018) Outcomes of transcatheter tricuspid valve-in-valve implantation in patients with ebstein anomaly. Am J Cardiol 121:262-268 